\title{
The effective pressure law for permeability of clay-rich sandstones
}

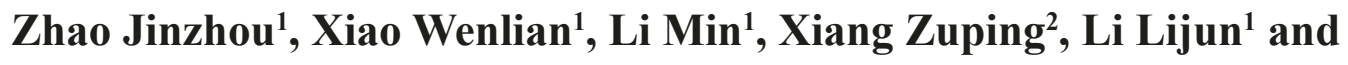 \\ Wang Jun ${ }^{1}$ \\ ${ }^{1}$ State Key of Oil and Gas Reservoir Geology and Exploitation, Southwest Petroleum University, Chengdu, Sichuan 610500, \\ China \\ ${ }^{2}$ Exploration \& Development Research Institute, Sinopec Southwest Branch, Chengdu, Sichuan 610081, China \\ (C) China University of Petroleum (Beijing) and Springer-Verlag Berlin Heidelberg 2011
}

\begin{abstract}
To study the relative sensitivity of permeability to pore pressure $P_{\mathrm{p}}$ and confining pressure $P_{\mathrm{c}}$ for clay-rich rocks, permeability measurements were performed on samples of four clay-rich sandstones. A new method (hereafter denoted the "slide method") was developed and used for analyzing the permeability data obtained. The effective pressure coefficients for permeability $n_{k}$ were calculated. The values of $n_{k}$ were found to be greater than 1.0 and insensitive to changes in pressure. These results confirmed observations previously made on clay-rich rocks. Also, the coefficients $n_{k}$ obtained had different characteristics for different samples because of differences in the types of clay they contained. The effective pressure law $\left(\sigma_{\text {eff }}=P_{\mathrm{c}}-n_{k} P_{\mathrm{p}}\right)$ determined using the slide method gave better results about $k\left(\sigma_{\text {eff }}\right)$ than classic Terzaghi's law $\left(\sigma_{\text {eff }}=P_{\mathrm{c}}-P_{\mathrm{p}}\right)$.
\end{abstract}

Key words: Permeability, effective pressure coefficient, slide method, clay, sandstones

\section{Introduction}

The functional relationship among permeability $k$, confining pressure $P_{\mathrm{c}}$, and pore pressure $P_{\mathrm{p}}$ can be expressed as $k=f\left(\sigma_{\mathrm{eff}}\right) f\left(P_{\mathrm{c}}-n_{k} P_{\mathrm{p}}\right)$, where $P_{\mathrm{c}}-n_{k} P_{\mathrm{p}}$ is the effective pressure $\sigma_{\text {eff }}$ and $n_{k}$ the effective pressure coefficient for permeability, a measure of the sensitivity of permeability to pore pressure relative to the sensitivity to confining pressure (Bernabé, 1987; Al-Wardy and Zimmerman, 2004). Applying the effective pressure law for permeability helps understand how permeability changes with pore pressure in reservoirs and allows the setting up of an optimal production strategy. So the effective pressure coefficient for permeability is important for oil and gas production activities.

A large amount of experimental work on the permeability effective pressure law has been reported. Three groups of experimental results can be summarized: 1) $n_{k}$ equals 1.0 (Brace et al, 1968; Coyner, 1984; Bernabé, 1987). 2) $n_{k}$ ranges from 0 to 1.0 (Nur et al, 1980; Bernabé, 1986; Warpinski and Teufel, 1992; Zheng et al, 2008; Li and Xiao, 2008; Li et al, 2009a; 2009b). Nur et al (1980) studied two artificial rocks and observed that $n_{k}$ were constant ( $n_{k}$ values of 0.43 and 0.86 ) while the others found that $n_{k}$ varied with confining pressure and pore pressure. 3) $n_{k}$ values are greater than 1.0

*Corresponding author. email: joshxiao@163.com Received October 17, 2010
(Zoback and Byerlee, 1975; Nur et al, 1980; Al-Wardy and Zimmerman, 2004; Ghabezloo et al, 2009), indicating that pore pressure has more effect on permeability than confining pressure. Ghabezloo et al (2009) found that $n_{k}$ was variable while the others observed constant $n_{k}$.

Theoretical studies of permeability effective pressure coefficients are sparse. For single-mineral rocks, Bernabé (1986) calculated $n_{k}$ on the basis of a "tunnel" crack with an elliptical cross-section in an infinite body. He found that $n_{k}$ is a function of the crack aspect ratio $\varepsilon$ (the ratio of the short to the long cross-sectional dimensions) and the Poisson' ratio $v$ of the solid phase, changing from $1 / 2(1-v)$ for $\varepsilon=$ 1.0 (cylindrical channel with circular cross section) to 1.0 for $\varepsilon=0$ (infinitely thin crack). Berryman (1992) obtained $n_{k}$ expression on the assumption of a homogenous, oneconstituent mineral frame. Furthermore he pointed out that the range of $n_{k}$ was [ $\left.\phi 1.0\right]$, where $\phi$ is the porosity. For twoconstituent rocks, Zoback and Byerlee (1975) proposed the conceptual "clay-shell" model to explain why $n_{k}$ was observed greater than 1.0. Al-Wardy and Zimmerman (2004) derived another clay-particle model and developed analytic solutions for $n_{k}$ for both the clay-shell and clay-particle models. They found that $n_{k}$ is related to clay content and the elastic moduli of the rock and the clay. Berryman (1992) presented an equivalent two-constituent model of porous rocks and deduced the expression of $n_{k}$. His model can be used to interpret why $n_{k}$ is observed to be significantly greater 
than unity in rocks containing clays.

In this paper, we conducted a laboratory study aimed at determining the value of $n_{k}$ in clay-rich sandstones. One important goal was to investigate the effect of clay on permeability at different pressures. So permeability measurements were performed on rock samples subjected to cycles of pore pressure. The "slide method" was developed and used for analyzing the experimental data. The results showed that the measured values of $n_{k}$ were greater than 1.0 and affected by the types of clay present in the various rocks.

\section{Materials and methods}

\subsection{Rock samples}

Four samples were selected for permeability measurements and their properties are listed in Table 1. X-ray experiments showed that the amount of clay present in each sample is $22.5 \%, 20.3 \%, 15.0 \%$ and $19.0 \%$ respectively. Clay minerals mainly consisted of mixed layer illite/smectite (26\%-40\%) and mixed layer chlorite/smectite (31\%-48\%). Sample S4, in which kaolinite was not detected, had greater amounts of illite and chlorite than the other samples.

Table 1 The types and content of clay minerals

\begin{tabular}{|c|c|c|c|c|c|c|c|c|c|}
\hline \multirow{2}{*}{ Sample } & \multirow{2}{*}{$\begin{array}{l}\text { Permeability } \\
\mathrm{mD}\end{array}$} & \multirow{2}{*}{$\begin{array}{c}\text { Porosity } \\
\quad \%\end{array}$} & \multirow{2}{*}{$\begin{array}{c}\text { Clay } \\
\%\end{array}$} & \multicolumn{6}{|c|}{ Clay mineral, \% } \\
\hline & & & & S & $\mathrm{I} / \mathrm{S}$ & 1 & K & C & $\mathrm{C} / \mathrm{S}$ \\
\hline S1 & 0.299 & 9.89 & 22.5 & 20 & 35 & 10 & 2 & 2 & 31 \\
\hline S2 & 0.561 & 12.31 & 20.3 & - & 39 & 8 & - & 6 & 47 \\
\hline S3 & 0.764 & 13.02 & 15.0 & - & 40 & 7 & 2 & 3 & 48 \\
\hline S4 & 0.139 & 8.53 & 19.0 & - & 26 & 28 & - & 11 & 35 \\
\hline
\end{tabular}

Notes: S: Smectite; I: Illite; K: Kaolinite; C: Chlorite; I/S: Mixed layer illite/ smectite; C/S: Mixed layer chlorite/smectite

\subsection{Experimental procedure}

The permeability measurements were conducted with nitrogen gas as the pore fluid so that any chemical and capillary effects that might arise from clay/water reactions and imperfect saturation could be minimized. The measurement apparatus was described in detail in a previous paper ( $\mathrm{Li}$ et al, 2009a; 2009b). Three cycles of pore pressure with different confining pressures were performed for each sample, and the confining pressure and pore pressure values were set according to reservoir conditions. The measurements in each test were repeated five times and averaged to determine permeability. The viscosities of nitrogen gas at different pressures and temperatures were obtained from the tables of the Beijing Chemical Industrial Company Inc. (1979).

Using nitrogen may cause problems at low pore pressure because of the Klinkenberg effect (Klinkenberg, 1941; Li et al, 2009a). However, the minimum pore pressure in our tests was $6 \mathrm{MPa}$ so that the Klinkenberg corrections can be neglected (Warpinski and Teufel, 1992; Li et al, 2009a; $2009 b)$. Also the study of Bernabé $(1986 ; 1987)$ and Li et al (2009a; 2009b) revealed that history effects had essentially vanished after two seasoning cycles. So the samples were subjected to at least two seasoning cycles to avoid loading history effects.

\subsection{Slide method}

From the definition of the effective pressure law, the effective pressure coefficient for permeability, $n_{k}$, can be defined as follows (Bernabé, 1986; 1987):

$$
n_{k}=-\frac{\left(\partial k / \partial P_{\mathrm{p}}\right)_{P_{\mathrm{c}}}}{\left(\partial k / \partial P_{\mathrm{c}}\right)_{P_{\mathrm{p}}}}
$$

The two partial derivatives in Eq. (1) can be evaluated by calculating the variations of pressure through changing $P_{\mathrm{c}}$ by $\delta P_{\mathrm{c}}$ and changing $P_{\mathrm{p}}$ by $\delta P_{\mathrm{p}}$ independently to make the variations $\delta k$ of permeability the same, so Eq. (1) of $n_{k}$ is then given by:

$$
n_{k}=\left(\frac{\delta P_{\mathrm{c}}}{\delta P_{\mathrm{p}}}\right)_{k}
$$

The calculation procedures of $n_{k}$ are as follows:

1) Establishing the relationship among permeability $k$, confining pressure $P_{\mathrm{c}}$, and pore pressure $P_{\mathrm{p}}$ by the quadratic response-surface method ( $\mathrm{Li}$ et al, 2009a; 2009b).

$$
k^{(\lambda)}=a_{1}+a_{2} P_{\mathrm{c}}+a_{3} P_{\mathrm{p}}+a_{4} P_{\mathrm{c}}^{2}+a_{5} P_{\mathrm{c}} P_{\mathrm{p}}+a_{6} P_{\mathrm{p}}^{2}
$$

Here, we used the Box-Cox transformation, and $k^{(\lambda)}=\left(\left(k / k_{0}\right)^{\lambda}-1\right) / \lambda$, where $k^{(\lambda)}$ denotes the transformed permeability and $k_{0}$ is a normalizing constant. The parameter $\lambda$ was normally expected to lie between -3 and +3 , with $\lambda=0$ corresponding to log transformation. The coefficients $a_{i}$ were calculated by least squares regression. Thus, if we combine Eq. (1) with Eq. (3), the values of $n_{k}$ can be obtained by the response-surface method ( $\mathrm{Li}$, et al, 2009a; 2009b).

2) Calculating the coordinates of two points in the confining pressure-pore pressure plane (e.g. $M\left(P_{\mathrm{cl}}, P_{\mathrm{pl}}\right)$ and $\left.N\left(P_{\mathrm{c} 2}, P_{\mathrm{p} 2}\right)\right)$, based on Eq. (3), when $\delta k$ is equal to zero. If we know the values of any three among $P_{\mathrm{cl}}, P_{\mathrm{p} 1}, P_{\mathrm{c} 2}$ and $P_{\mathrm{p} 2}$, the remaining pressure can be solved using Eq. (4).

$$
\begin{aligned}
& a_{2} P_{\mathrm{c} 1}+a_{3} P_{\mathrm{p} 1}+a_{4} P_{\mathrm{c} 1}^{2}+a_{5} P_{\mathrm{c} 1} P_{\mathrm{p} 1}+a_{6} P_{\mathrm{p} 1}^{2} \\
& =a_{2} P_{\mathrm{c} 2}+a_{3} P_{\mathrm{p} 2}+a_{4} P_{\mathrm{c} 2}^{2}+a_{5} P_{\mathrm{c} 2} P_{\mathrm{p} 2}+a_{6} P_{\mathrm{p} 2}^{2}
\end{aligned}
$$

3) Calculating the effective pressure coefficient $n_{k}$. Assuming the point $M\left(P_{\mathrm{cl}}, P_{\mathrm{pl}}\right]$ is given, if we slide $P_{\mathrm{cl}}$ by $\delta P$ (Fig. 1(a)) and $P_{\mathrm{c} 2}=P_{\mathrm{c} 1} \pm \delta P, P_{\mathrm{p} 2}$ can be solved $\left(\mathrm{sol} P_{\mathrm{p} 2}\right)$; if we slide $P_{\mathrm{p} 1}$ by $\delta P$ (Fig. (1b)) and $P_{\mathrm{c} 2}=P_{\mathrm{c} 1} \pm \delta P, P_{\mathrm{c} 2}$ can be 
solved $\left(\mathrm{sol} P_{\mathrm{c} 2}\right)$. Thus, there are four solutions satisfying Eq. (4). So $n_{k}$ can be expressed as follows:

$$
\begin{aligned}
& n_{k}=\left(\frac{\delta P_{\mathrm{c}}}{\delta P_{\mathrm{p}}}\right)_{k}=\left(\frac{P_{\mathrm{c} 1}-P_{\mathrm{c} 2}}{P_{\mathrm{p} 1}-P_{\mathrm{p} 2}}\right)_{k}=\left(\frac{\delta P}{P_{\mathrm{p} 1}-\mathrm{sol} P_{\mathrm{p} 2}}\right)_{k} \\
& \operatorname{or}\left(\frac{\delta P}{P_{\mathrm{p} 1}-\mathrm{sol} P_{\mathrm{p} 2}}\right)_{k} \operatorname{or}\left(\frac{P_{\mathrm{c} 1}-\mathrm{sol} P_{\mathrm{c} 2}}{-\delta P}\right)_{k} \operatorname{or}\left(\frac{P_{\mathrm{c} 1}-\mathrm{sol} P_{\mathrm{c} 2}}{-\delta P}\right)_{k}
\end{aligned}
$$

The sliding value $\delta P$ is commonly the same and, furthermore, is chosen to be small (e.g. $1 \mathrm{MPa}$ ). All values calculated are averaged for the determination of effective pressure coefficient $n_{k}$. It should be noted that we can get two roots for either $P_{\mathrm{c} 2}$ or $P_{\mathrm{p} 2}$ when solving Eq. (4). However, the appropriate root can be identified based on Eq. (5).

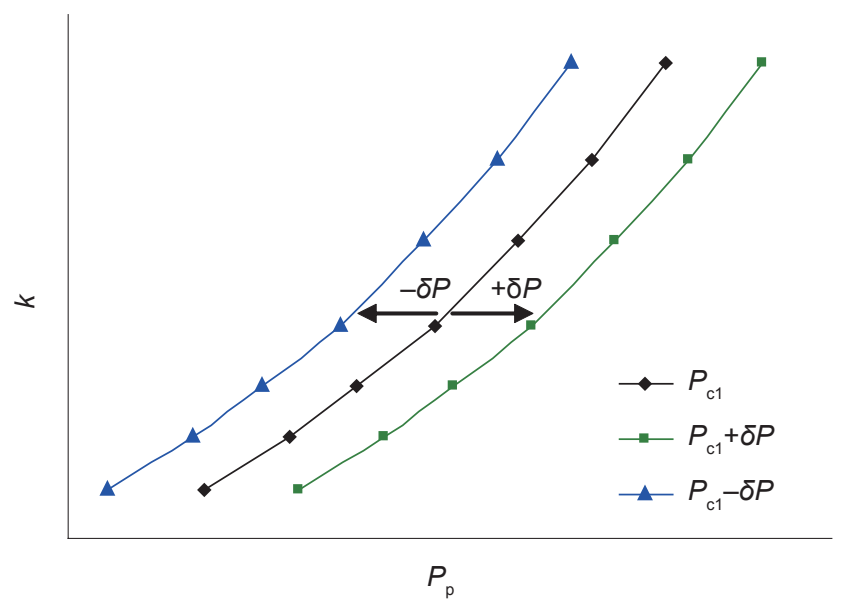

(a) Sliding confining pressure $P_{c}$

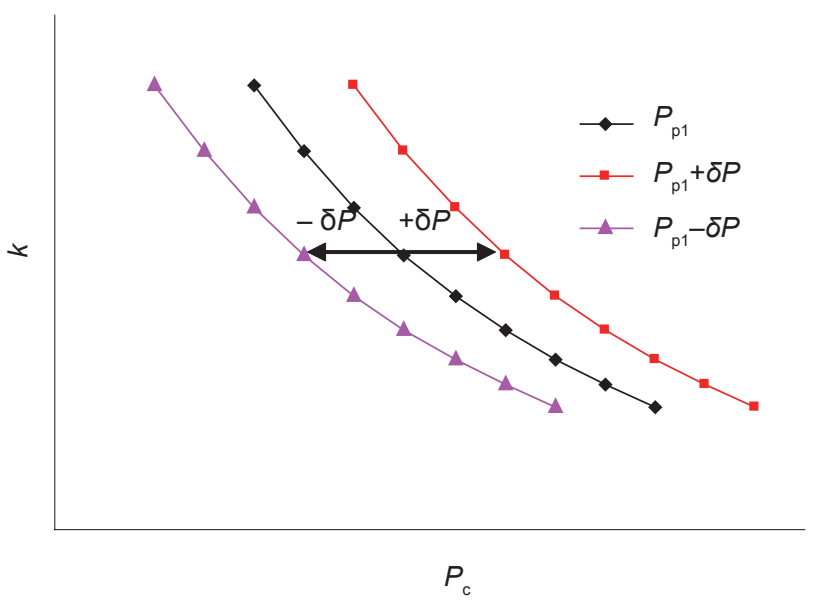

(b) Sliding pore pressure $P_{\mathrm{p}}$

Fig. 1 Schematic diagrams of the slide method

\section{Results}

\subsection{Permeability measurements}

Fig. 2 shows the permeability results for four samples at different confining pressures while cycling pore pressure ("L" and "U" stand for decreasing pore pressure (loading process) and increasing pore pressure (unloading process) respectively). The results show that permeability decreased with increasing confining pressure, and increased with increasing pore pressure. We observed differences in permeability during decreasing and increasing cycles of $P_{\mathrm{p}}$, which showed that hysteresis effects were still present, although history effects were eliminated by seasoning the samples.

\subsection{Effective pressure coefficients}

The values of $n_{k}$ can be calculated by two methods: the response-surface method and the slide method. The results were listed in Table 2. The values of $n_{k}$ in the decreasing $P_{\mathrm{p}}$ cycle were different from the ones in the increasing $P_{\mathrm{p}}$ cycle at the equivalent pressure for the same $P_{\mathrm{c}}$, due to stress hysteresis.

Table 2 The values of effective pressure

\begin{tabular}{cccccc}
\hline & \multicolumn{3}{c}{ The effective pressure coefficient $n_{k}$} \\
\cline { 2 - 3 } Sample & \multicolumn{2}{c}{ The response-surface method } & & \multicolumn{2}{c}{ The slide method } \\
\cline { 2 - 3 } \cline { 5 - 6 } & $\begin{array}{c}\text { Decreasing } \\
\text { pore pressure }\end{array}$ & $\begin{array}{c}\text { Increasing } \\
\text { pore pressure }\end{array}$ & & $\begin{array}{c}\text { Decreasing } \\
\text { pore pressure }\end{array}$ & $\begin{array}{c}\text { Increasing } \\
\text { pore pressure }\end{array}$ \\
\hline S1 & $0.75-1.65$ & $0.34-1.72$ & & 1.16 & 0.93 \\
S2 & $0.14-5.59$ & $0-8.31$ & & 4.04 & 2.47 \\
S3 & $3.74-16.59$ & $2.19-5.88$ & & 6.16 & 4.05 \\
S4 & $0.78-8.15$ & $0.54-13.19$ & 2.61 & 1.89 \\
\hline
\end{tabular}

We needed a way to assess the validity of $n_{k}$, because the two methods produced different values. The most natural method was to compare the two effective pressure laws determined here: $\sigma_{\text {eff }}=P_{\mathrm{c}}-n_{k \mathrm{~s}} P_{\mathrm{p}}\left(n_{k \mathrm{~s}}\right.$ was computed by the slide method) and $\sigma_{\text {eff }}=P_{\mathrm{c}}-n_{k \mathrm{~s}} P_{\mathrm{p}}\left(n_{k \mathrm{r}}\right.$ was computed by the responsesurface method). This can be done graphically by comparing plots of $k$ versus $\sigma_{\text {eff }}$ for both effective pressure laws and observing which one gave the lowest dispersion of the data points. The comparison can be quantified by calculating the correlation coefficient $R^{2}$ (the range of $R^{2}$ was $[0,1]$, which characterizes the correlation among the variables - the bigger $R^{2}$ is, the more closely the variables are related to each other, and the smaller is the root mean square of residuals $s$. Exponential and polynomial functions were used respectively for $k-\sigma_{\text {eff }}$ curve-fitting. The results of this analysis were in Table 3.

From Table 3, it was concluded that: 1) Whatever the curve-fitting function was, for every sample the correlation coefficient $R^{2}$ based on the slide method $\left(R_{\mathrm{s}}{ }^{2}\right)$ was always bigger than the one based on the response-surface method $\left(R_{\mathrm{r}}^{2}\right)$, and the root mean square of residuals $s_{\mathrm{s}}$ was smaller than $s_{\mathrm{r}}$. 2) The coefficient $R^{2}$ from the polynomial-fitting function was bigger than the one from the exponential-fitting function, but s from the polynomial-fitting function was lower than the one from the exponential-fitting function. Therefore, 


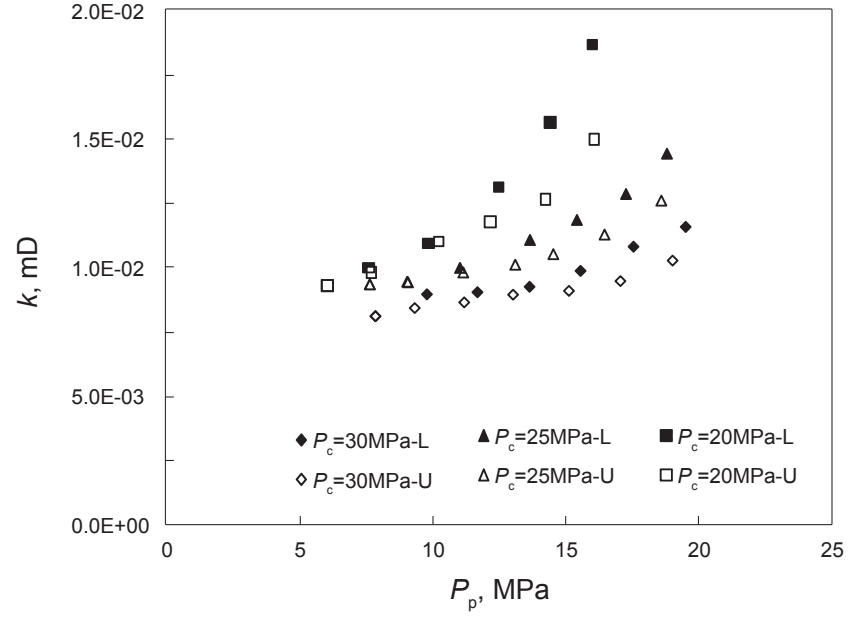

(a) Sample S1

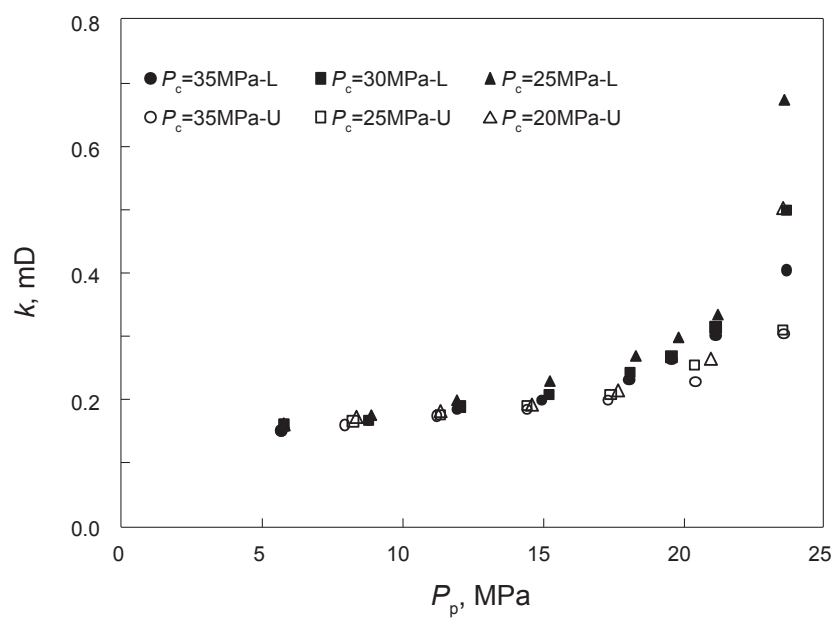

(c) Sample S3

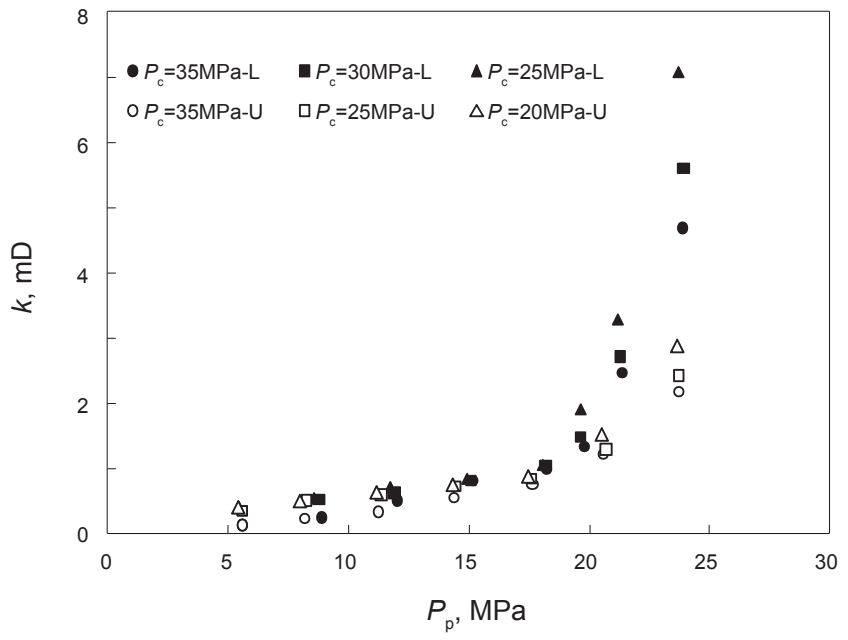

(b) Sample S2

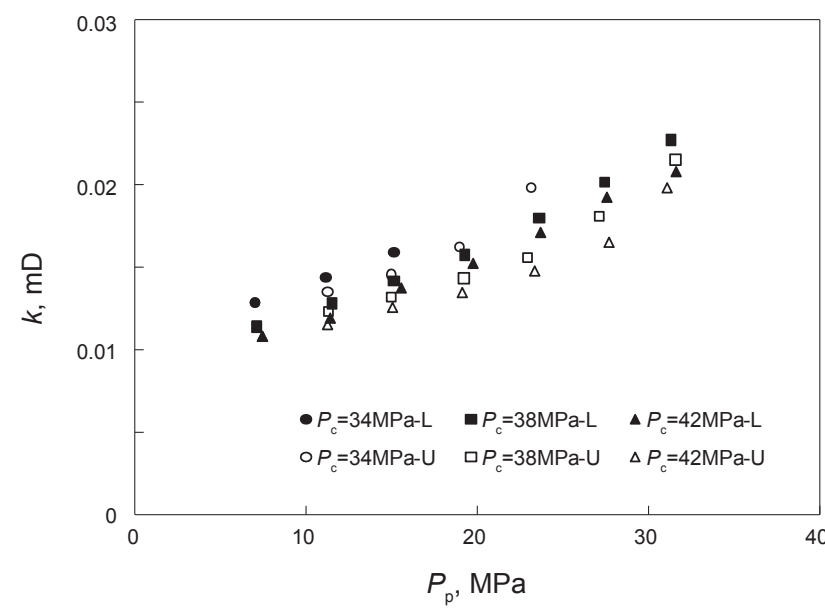

(d) Sample S4

Fig. 2 The relation of $k-P_{\mathrm{c}}-P_{\mathrm{p}}$

Table 3 Correlation coefficients $R^{2}$ and root mean square of residuals $s$

\begin{tabular}{|c|c|c|c|c|c|c|c|c|c|}
\hline \multirow{2}{*}{ Sample } & \multirow{2}{*}{ Cycle } & \multicolumn{4}{|c|}{ Exponential function } & \multicolumn{4}{|c|}{ Polynomial function } \\
\hline & & $R_{\mathrm{r}}^{2}$ & $s_{\mathrm{r}}, \mathrm{mD}$ & $R_{\mathrm{s}}{ }^{2}$ & $s_{\mathrm{s}}, \mathrm{mD}$ & $R_{\mathrm{r}}^{2}$ & $s_{\mathrm{r}}, \mathrm{mD}$ & $R_{\mathrm{s}}^{2}$ & $s_{\mathrm{s}}, \mathrm{mD}$ \\
\hline \multirow{2}{*}{$\mathrm{S} 1$} & Decreasing $P_{\mathrm{p}}$ & 0.6440 & $3.55 \mathrm{E}-04$ & 0.8830 & $2.22 \mathrm{E}-04$ & 0.7192 & $3.12 \mathrm{E}-04$ & 0.9466 & $1.36 \mathrm{E}-04$ \\
\hline & Increasing $P_{\mathrm{p}}$ & 0.7628 & $1.93 \mathrm{E}-04$ & 0.9079 & $1.21 \mathrm{E}-04$ & 0.7772 & $1.78 \mathrm{E}-04$ & 0.9642 & $8.10 \mathrm{E}-05$ \\
\hline \multirow{2}{*}{ S2 } & Decreasing $P_{\mathrm{p}}$ & 0.9231 & $4.21 \mathrm{E}+00$ & 0.9052 & $1.55 \mathrm{E}-01$ & 0.9352 & $1.31 \mathrm{E}+00$ & 0.9800 & 7.03E-02 \\
\hline & Increasing $P_{\mathrm{p}}$ & 0.8096 & 7.87E-02 & 0.9130 & 4.47E-02 & 0.8619 & $6.05 \mathrm{E}-02$ & 0.9449 & $3.83 \mathrm{E}-02$ \\
\hline \multirow{2}{*}{$\mathrm{S} 3$} & Decreasing $P_{\mathrm{p}}$ & 0.3712 & $2.28 \mathrm{E}-02$ & 0.8391 & $1.32 \mathrm{E}-02$ & 0.3362 & 4.66E-02 & 0.9960 & $9.53 \mathrm{E}-03$ \\
\hline & Increasing $P_{\mathrm{p}}$ & 0.8626 & $8.26 \mathrm{E}-03$ & 0.7987 & 9.87E-03 & 0.8882 & $5.86 \mathrm{E}-03$ & 0.9790 & $2.50 \mathrm{E}-03$ \\
\hline \multirow{2}{*}{ S4 } & Decreasing $P_{\mathrm{p}}$ & 0.1097 & $8.10 \mathrm{E}-04$ & 0.9741 & $1.24 \mathrm{E}-04$ & 0.1145 & $8.06 \mathrm{E}-04$ & 0.9900 & $9.63 \mathrm{E}-05$ \\
\hline & Increasing $P_{\mathrm{p}}$ & 0.2152 & 7.15E-04 & 0.9278 & $1.90 \mathrm{E}-04$ & 0.3041 & 7.16E-04 & 0.9650 & $1.00 \mathrm{E}-04$ \\
\hline
\end{tabular}

Notes: Subscripts $r$ and s stand for the response-surface method and the slide method respectively

the $k-\sigma_{\text {eff }}$ curves were fitted better by the polynomial function should be used to determine the effective pressure law. and the slide method gave better results than the response- Moreover, we observed that the values of $n_{k}$ obtained with surface method (Fig. 3). So we conclude that the slide method the slide method were constant and greater than 1.0 (Table 
2), demonstrating that pore pressure had more effect on permeability than confining pressure.

There is less scatter for $k\left(\sigma_{\text {eff }}\right)$ with the slide method (solid circles) than both for $k\left(\sigma_{\text {eff }}\right)$ with the response-surface method (open circles) and for $k\left(\sigma_{\text {eff }}\right)$ with Terzaghi's law $\sigma_{\text {eff }}=P_{\mathrm{c}}-$ $P_{\mathrm{p}}$ (start).

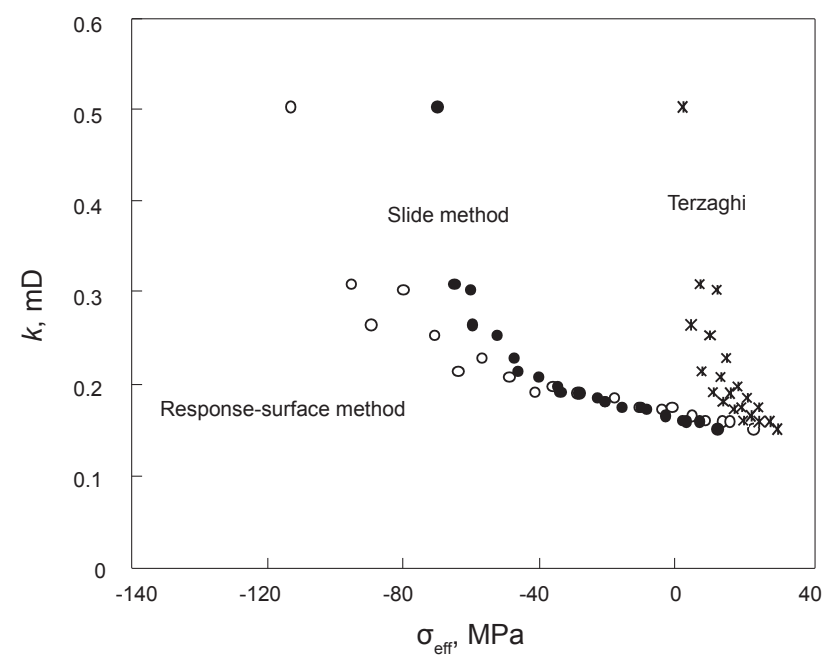

Fig. 3 Assessment of the quality of the effective pressure law for Sample S3

\section{Discussion}

In the past, Terzaghi's law $\left(\sigma_{\mathrm{eff}}=P_{\mathrm{c}}-P_{\mathrm{p}}\right)$ has usually been referred to as the classic effective pressure law and often applied to analyze rock behavior. Therefore, we compared Terzaghi's law $\left(\sigma_{\text {eff }}=P_{\mathrm{c}}-P_{\mathrm{p}}\right)$ to the effective pressure law obtained using the slide method. We denote $R_{\mathrm{t}}^{2}$ and $s_{\mathrm{t}}$ the corresponding correlation coefficients and root mean square of residuals. It was found that 1) $R_{\mathrm{t}}^{2}$ values for Samples S1, S2, S3, and S4 are 0.9535, 0.7743, 0.6931, and 0.9851 in decreasing $P_{\mathrm{p}}$ cycles, and $0.9643,0.8442,0.6873$, and 0.9713 in increasing $P_{\mathrm{p}}$ cycles. 2) The corresponding $s_{\mathrm{t}}(\mathrm{mD})$ values for Samples S1, S2, S3, and S4 are 1.27E-04, 0.231, 1.56E-02, and $1.05 \mathrm{E}-04$ in decreasing $P_{\mathrm{p}}$ cycles, and 7.14E-05, 8.35E-02, $1.09 \mathrm{E}-02$, and $1.14 \mathrm{E}-04$ in increasing $P_{\mathrm{p}}$ cycles. Therefore, $R_{\mathrm{t}}^{2}$ was less than $R_{\mathrm{s}}{ }^{2}$ and $s_{\mathrm{t}}$ was larger than $S_{\mathrm{s}}$ for Samples S2, S3, and S4, but for Sample S1 they were almost identical because $n_{k}$ was close to 1.0 . These results suggest that the effective pressure law obtained with the slide method gave better results than Terzaghi's law (Fig. 3).

In addition, the results obtained in this paper confirm that $n_{k}$ is constant and higher than 1.0 in sandstones with a substantial amount of clays (Zoback and Byerlee, 1975; Nur et al, 1980; Berryman, 1992; Al-Wardy and Zimmerman, 2004). From X-ray analysis data, the clay content in the sandstone samples was more than $10 \%$.

However, in Sample S4 the clay content was as high as $19 \%$ but $n_{k}$ was relatively small. From the X-ray analysis, it was found that Sample S4 had more illite and chlorite, and less mixed layers than the other samples, but no smectite and kaolinite. As it is known that smectite, kaolinite, and greater mixed layers are easily compressed, our results suggest that greater value of $n_{k}$ may be correlated with greater compressibility. On the contrary, illite and chlorite are much harder to compress because the crystallographic interplanar spacing of illite and chlorite is smaller (Ren, 1988; Yang and Ye, 2003; Zhao and Zhang, 1990). In other words, their compressibility is smaller, which makes the value of $n_{k}$ smaller. In summary, we found that the type of clay also had an influence on the value of $n_{k}$.

\section{Conclusions}

1) The effective pressure coefficients $n_{k}$ are constant and greater than 1.0 for clay-rich sandstones, which confirms that permeability is more sensitive to change in pore pressure than to change in confining pressure.

2) The slide method was developed and found to be adequate for calculating the coefficient $n_{k}$.

3) The effective pressure law with the slide method $\left(n_{k}>1.0\right)$ gave a better relationship between permeability and effective pressure than Terzaghi's law $\left(n_{k}=1.0\right)$.

4) The effective pressure coefficient $n_{k}$ was affected by clay mineralogy.

\section{Acknowledgements}

The authors would like to express their appreciation to Professor Yves Bernabé for his helpful discussion and suggestions. This work was supported by a grant from the National Natural Science Foundation of China (Grant No. 50774064) and by the Open Fund PLN0802 of the State Key Laboratory of Oil and Gas Reservoir Geology and Exploitation (Southwest Petroleum University).

\section{References}

Al-Wardy W and Zimmerman R W. Effective stress law for the permeability of clay-rich sandstones. Journal of Geophysical Research. 2004. 109. B04203

Bernabé Y. The effective pressure law for permeability in Chelmsford granite and Barre granite. International Journal of Rock Mechanics and Mining. 1986. 23(3): 267-275

Bernabé Y. The effective pressure law for permeability during pore pressure and confining pressure cycling of several crystalline rocks. Journal of Geophysical Research. 1987. 92(B1): 649-657

Berryman J G. Effective stress for transport properties of inhomogeneous porous rock. Journal of Geophysical Research. 1992. 97(B12): 17409-17424

Brace W F, Walsh J B and Frangos W T. Permeability of granite under high pressure. Journal of Geophysical Research. 1968. 73(6): 22252236

Coyner K B. Effects of stress, pore pressure and pore fluid on bulk strain, velocity, and permeability in rocks. Ph.D Thesis. Cambridge: Massachusetts Institute of Technology. 1984

Ghabezloo S, Sulem J, Sylvine G. Effective stress law for the permeability of a limestone. International Journal of Rock Mechanics and Mining Sciences. 2009. 46 (2): 297-306

Klinkenberg L J. The permeability of porous media to liquids and gases. Drilling and Productions Practices. 1941. 200-213

Li M, Bernabé Y, Xiao W L, et al. Effective pressure law for permeability of E-bei sandstones. Journal of Geophysical Research 2009a. 114: B07205

Li M, Xiao W L, Guo X, et al. Laboratory study of the effective pressure 
law for permeability of the low permeability sandstones from the Ta-Ba-Miao Area, Inner Mongolia. Chinese Journal of Geophysics. 2009b. 52(6): 1402-1413

Li M and Xiao W L. Experimental study of permeability-effective-stress law in low-permeability sandstone reservoir. Chinese Journal of Rock Mechanics and Engineering. 2008. 27(s2): 3535-3540 (in Chinese)

Nur A, Walls J D, Winkler, et al. Effects of fluid saturation on waves in porous rock and relations to hydraulic permeability. SPE Journal.1980. 26(2): 450-458

Ren L F. Intermediate structures of clay minerals during transformation. Acta Sedimentologica Sinica. 1988. 6(1): 80-87 (in Chinese)

Warpinski N R and Teufel L W. Determination of the effective stress law for permeability and deformation in low-permeability rocks. SPE
Journal. 1992. 7(2): 123-131

Yang X Z and Ye N J. Gibbs free energies of formation for mixed-layer illite-montmorillonite in the process of montmorillonite illitization. Geology-Geochemistry. 2003. 31(3): 20-25 (in Chinese)

Zhao X Y and Zhang Y Y. Clay Minerals and Clay Mineral Analysis. Beijing: Haiyang Press. 1990 (in Chinese)

Zheng L L, Li M, Xiao W L, et al. Determination of the effective-stress law by the maximum-likelihood approach. Xinjiang Petroleum Geology. 2008. 29(6): 747-749 (in Chinese)

Zoback M D and Byerlee J D. Permeability and effective stress. AAPG Bulletin. 1975. 59(1): 154-158

(Edited by Sun Yanhua) 